\title{
Admission Hyperglycemia and its Implications on Outcome in Patients Attending Medical Intensive Care Units at Assiut University Hospital
}

\author{
LOBNA F. EL-TOONY, M.D.; MONA H. EL-ZOHRI, M.D. and AML A. ABO EL-GHAIT, M.Sc.
}

The Department of Internal Medicine, Faculty of Medicine, Assiut University, Assiut, Egypt

\begin{abstract}
Background: Admission hyperglycemia is defined as any blood glucose level greater than $140 \mathrm{mg} / \mathrm{dl}(>7.8 \mathrm{mmol} / \mathrm{l})$ in Critical Care Unit according to American Diabetes Association 2015. Stress hyperglycemia is related to multiple causes as inflammatory and neuro-endocrine derangements in critically ill patients, which lead to insulin resistance and high hepatic glucose output.
\end{abstract}

Aim of Work: To determine the frequency, in-hospital mortality and length of stay in a cohort of patients with admission hyperglycemia in unselected acute medically ill patients admitted to Medical Intensive Care Units (medical ICU and CCU) attending Assuit University Hospital, Internal Medicine Department. And to evaluate whether admission hyperglycemia or other comorbid conditions responsible for outcome of critical ill patients.

Patients and Methods: Aprospective, observational, noninterventional study involved 170 patients were admitted at ICU Unit of Internal Medicine Department at Assiut University Hospitals during the period between July 1 st 2016 and $30^{\text {th }}$ December 2016 were enrolled. Measurement of random blood glucose on admission to ICU if less than $140 \mathrm{mg} / \mathrm{dl}$ : Catrgorized as normoglycemic. If more than 140mg/dl: Catrgorized as hyperglycemic: Follow-up blood glucose on days of admission to ICU every 8 hours till either discharge or death or maximum four day in addition to fasting, postprandial glucose, $\mathrm{HbA1C}$, Liver Function Test (LFT), Complete Blood Count (CBC) \& kidney function tests, serum sodium, serum potassium, arterial blood gases and calculation of APACHE II score.

Results: The present study included 170 patient, 35.3\% were normoglycemic and $64.7 \%$ were hyperglycemic which further subdivided into $43 \%$ known diabetics, $14.1 \%$ stress hyperglycemia and $7.6 \%$ newly discovered diabetics. Percentage of survivors was $72.9 \%$ versus non survivors was $27.1 \%$. Median hospital stay for all patients was 6 (4-28) days with in hospital mortality was $46(27.1 \%)$ patients. It was noticed that frequency of non- survivors was higher in patients with hyperglycemic versus survivors.

Conclusion: Stress hyperglycemia and diabetes were independent predictors for in hospital mortality in patients with admission hyperglycemia attending ICU.

Correspondence to: Dr. Lobna F. El-Toony, The Department of Internal Medicine, Faculty of Medicine, Assiut University, Assiut, Egypt
Key Words: Admission hyperglycemia - Stress induced hyperglycemia - HbAlc-APACHE II score - ICU.

\section{Introduction}

STRESS-Induced Hyperglycemia (SIH) is a common finding among critically ill patients, particularly among cardiovascular patients, neurocritical patients, and patients undergoing surgical procedures, even in the absence of preexisting DM [1] SIH occurs in critically ill patients in whom glucose tolerance was previously normal, with hyperglycemia resolving following recovery [2]. SIH is related to multiple causes that include inflammatory and neuro-endocrine derangements in critically ill patients, which lead to insulin resistance and high hepatic glucose output [3]. Stress-hyperglycemia is caused by endogenous and exogenous factors, Critical illness leads to activation of the Hypothalamic-Pituitary-Adrenal axis (HPA), which results in the release of cortisol. Cortisol stimulates gluconeogenesis and decreases glucose utilization. Other counter-regulatory hormones (glucagon, catecholamines and growth hormone) are also released [4]. Hypermetabolic state occurs in patients in a critical condition due to their disease, with intense activation of contraregulating hormones and cytokines, such as Tumour Necrosis Factor alpha (TNF-a), Interleukin 1 (IL-1) and Interleukin 6 (IL-6), which are important insulin resistance mediators, thereby causing hyperglycemia [5]. This usually resolves as the acute illness or medicosurgical stress decreases but a small study showed that $60 \%$ of patients with admission hyperglycemia had confirmed diabetes at 1 year [6]. Severe hyperglycemia, is a well-documented marker of illness severity, rather than a direct cause of poor outcome [7]. There is evidence that developing hyperglycemia during an illness or acute surgery increases morbidity, the number of days spent in the Intensive Care Unit (ICU) and in hospital, as well as the 
number of days with mechanically assisted respiration [8]. Stress hyperglycemia in critically ill patients is a common therapeutic challenge. There is no universally accepted insulin regimen for glycemic control in critically ill patients [9]. The American Diabetes Association 2016 recommends starting insulin in patients with persistent hyperglycemia above $180 \mathrm{mg} / \mathrm{dL}$ in critically ill patients, and to maintain the glycemic range between 140$180 \mathrm{mg} / \mathrm{dL}$. It also states that stricter glycemic control (110-140mg/dL) can be appropriate for certain patients, such those with acute cardiac ischemia or patients with acute neurological event to avoid hypoglycemia [10].

Aim of work: To determine the frequency, inhospital mortality and length of stay in a cohort of patients with admission hyperglycemia in unselected acute medically ill patients admitted to Medical Intensive Care Units (medical ICU and CCU) attending Assuit University Hospital, Internal Medicine Department. And evaluate whether admission hyperglycemia or other comorbid conditions responsible for outcome of critical ill patients.

\section{Patients and Methods}

The current study was a prospective, observational, non-interventional study involved 170 patients were admitted at ICU Unit of Internal Medicine Department at Assiut University Hospitals in period between July 1 st 2016 and 30th December 2016 were enrolled.

Inclusion criteria: Both male and female patients more than 18 years of age were hospitalized through the Intensive Care Units (medical ICU and $\mathrm{CCU}$ ) for critical medical conditions according to APACHE II score were included.

Exclusion criteria: Patient with hypoglycemia (hypoglycemia was defined as the presence of BG level $<70 \mathrm{mg} / \mathrm{dL}$ ) and patients who discharged against medical advice will excluded since outcome is unknown.

\section{All patients were subjected to the followings:}

Detailed history, clinical examination, systemic examination and laboratory investigation including random blood glucose on admission to ICU if less than 140mg/dl: Catrgorized as normoglycemic. If more than 140mg/dl: Catrgorized as hyperglycemic, then follow-up blood glucose on days of ICU every 8 hours till either discharge death or maximum four days in addition to fasting, postprandial glucose, HbA1C also, laboratory work including Liver Function Test (LFT), Complete Blood Count
(CBC), kidney function tests, serum sodium, serum potassium, arterial blood gases, calculation of APACHE II and calculation of length of stay by date of admission and date of discharge done.

\section{Statistical analysis:}

Data was collected and analyzed using SPSS (Statistical Package for the Social Science, Version 20, IBM, and Armonk, New York). Continuous data was expressed in the form of mean \pm SD while nominal data was expręssed in the form of frequency (percentage). Chi -test was used to compare the nominal data of different groups in the study while student $t$-test was used to compare mean of different two groups and ANOVA test for more than two groups. Multivariate regression analysis was used to determine the independent risk factors for mortality in patients admitted to ICU with hyperglycemia.

Ethics and consents: The study protocol was approved by the local Ethics Committee in Faculty of Medicine, Assiut University at 23 June 2015.

\section{Results}

The present study included 170 patients, $35.3 \%$ were normoglycemic and $64.7 \%$ were hyperglycemic subdivided into $43 \%$ known diabetics, $14.1 \%$ stress hyperglycemia and $7.6 \%$ newly discovered diabetics.

Demographic characteristics: It was found that there was no significant difference between the age of different group. Diabetic group had statistical significant high frequency of hypertension, chronic kidney disease and coronary artery disease ( $p$ value was $0.01,0.02$ and 0.04 respectively). Collagen diseases, in particular SLE, were significantly frequent in patients with stress hyperglycaemia [5 $(18.9 \%)$ with $p$-value $=0.011$. Presence of more than three comorbidities including DM was higher in diabetic group (42 (57.5\%)) compared to other groups with significant $p$-value (0.01).

Clinical characteristics: The majority of patients included in each group were overweight. There was wide range for the main cause of admission in each group in general myocardial infarction and pneumonia were the main cause of admission in the majority of all patients where each one occurred in $40(23.5 \%)$ patients from the total number.

Average daily blood glucose values for patients with hyperglycemia: The current study showed that diabetic and newly discovered DM had significant differences between them regarding average 
daily blood glucose over four days and $\mathrm{HbA1c}$ ( $p$ > 0.05 ) but both groups had significantly high values in comparison with patients with stress hyperglycaemia $(p<0.05)$ as shown in (Table 1$)$.

Hospital stay and outcome: Median hospital stay for all patients was 6 (4-28) days with in hospital mortality was $46(27.1 \%)$ patients out of the total patients (170). It was noticed that the patients with stress hyperglycemia associated with high mortality rate $(37 \%)$. Regarding causes of death, Myocardial Infarction (MI) and pneumonia were the commonest causes in all patients and each group.

Average daily blood glucose values for survivors vs. non-survivors: Although the range of hospital stay was higher in non-survivors than survivors
(4-23 vs. 4-28 day), yet this had no significant value $(p>0.05)$. It was noticed that frequency of non- survivors was higher in patients with hyperglycemic 39 (84.8) versus survivors as shown in (Table 3).

Multivariate regression analysis for predictors of in hospital mortality in patients with hyperglycemia: It was found that presence of $>3$ comorbidities $(95 \% \mathrm{CI}, \mathrm{OR}=1.2 ; p=0.00)$, APACHE II score $>15(95 \% \mathrm{CI}, \mathrm{OR}=1.2 ; p=0.03)$, stress hyperglycemia $(95 \% \mathrm{CI}, \mathrm{OR}=2.8 ; p=0.00)$ and diabetes $(95 \% \mathrm{CI}, \mathrm{OR}=1.2 ; p=0.00)$ were independent predictors for in hospital mortality in patients with hyperglycemia as shown in (Table 4).

Table (1): Average daily blood glucose values for those with hyperglycemia.

\begin{tabular}{|c|c|c|c|c|c|c|c|}
\hline Variables & $D(n=73)$ & $\mathrm{SH}(\mathrm{n}=24)$ & $\mathrm{ND}(\mathrm{n}=13)$ & $p$-value & $p$-value ${ }^{2}$ & $p$-value ${ }^{3}$ & $p$-value ${ }^{4}$ \\
\hline Hemoglobin A1 c & $9.21 \pm 2.96$ & $5.57 \pm 0.57$ & $9.41 \pm 2.04$ & $0.001(\mathrm{~S})$ & $0.001(\mathrm{~S})$ & $0.01(\mathrm{~S})$ & $0.04(\mathrm{~S})$ \\
\hline \multicolumn{8}{|c|}{ Blood glucose $(\mathrm{mg} / \mathrm{dl})$ : } \\
\hline 1st day & $278.23 \pm 45.95$ & $196.89 \pm 58.66$ & $283.44 \pm 55.11$ & $0.03(\mathrm{~S})$ & $0.001(\mathrm{~S})$ & $0.02(\mathrm{~S})$ & $0.01(\mathrm{~S})$ \\
\hline 2nd day & $255.33 \pm 67.39$ & $178.45 \pm 45.09$ & $304.84 \pm 66.09$ & $0.001(\mathrm{~S})$ & $0.01(\mathrm{~S})$ & $0.03(\mathrm{~S})$ & $0.03(\mathrm{~S})$ \\
\hline 3rd day & $232.39 \pm 55.66$ & $176.50 \pm 33.56$ & $252.61 \pm 76.09$ & $0.01(\mathrm{~S})$ & $0.02(\mathrm{~S})$ & $0.04(\mathrm{~S})$ & $0.001(\mathrm{~S})$ \\
\hline 4th day & $209.81 \pm 23.89$ & $171.11 \pm 24.01$ & $231.07 \pm 50.11$ & $0.001(\mathrm{~S})$ & $0.03(\mathrm{~S})$ & $0.02(\mathrm{~S})$ & $0.03(\mathrm{~S})$ \\
\hline
\end{tabular}

Data was expressed in form of mean \pm SD. $p$-value considered significant if $<0.05$.

$\mathrm{n}$ : Number. S: Significant.

NG : Normoglycemic. 1: Comparison among all groups.

D : Diabetic.

SH : Stress Hyperglycemia.

ND : Newly Discovered diabetes mellitus. $\quad 4$ : Comparison between stress hyperglycemia and newly discovered DM.

Table (2): Outcome and median hospital stay.

\begin{tabular}{|c|c|c|c|c|c|c|c|c|c|c|c|c|}
\hline Variables & $\begin{array}{c}\text { Total } \\
(\mathrm{n}=170)\end{array}$ & $\begin{array}{c}\mathrm{NG} \\
(\mathrm{n}=60)\end{array}$ & $\begin{array}{c}D \\
(n=73)\end{array}$ & $\begin{array}{c}\text { SH } \\
(n=24)\end{array}$ & $\begin{array}{c}\text { ND } \\
(n=13)\end{array}$ & $\begin{array}{c}p \text { - } \\
\text { value } 1\end{array}$ & $\begin{array}{c}p- \\
\text { value }^{2}\end{array}$ & $\begin{array}{c}p- \\
\text { value }^{3}\end{array}$ & $\begin{array}{c}p- \\
\text { value }^{4}\end{array}$ & $\begin{array}{c}p- \\
\text { value }^{5}\end{array}$ & $\begin{array}{c}p \text { - } \\
\text { value }^{6}\end{array}$ & $\begin{array}{c}p- \\
\text { value }^{7}\end{array}$ \\
\hline Hospital stay & $6(4-28)$ & $5.5(4-28)$ & $6(4-24)$ & $7(4-19)$ & $6(4-20)$ & 0.99 & 0.42 & $0.02(\mathrm{~S})$ & 0.039 & 0.43 & 0.96 & 0.35 \\
\hline In hospital death & $46(27.1)$ & $7(15.2)$ & $20(43.5)$ & $17(37.0)$ & $2(4.3)$ & 0.09 & $0.03(\mathrm{~S})$ & $0.001(\mathrm{~S})$ & 0.657 & $0.001(\mathrm{~S})$ & 0.50 & $0.001(\mathrm{~S})$ \\
\hline \multicolumn{13}{|l|}{ Cause of death: } \\
\hline MI & $18(10.6)$ & 7 (11.7) & $7(9.5)$ & $4(16.7)$ & $2(15.4)$ & $0.03(\mathrm{~S})$ & 0.70 & 0.72 & 0.46 & 0.46 & 0.62 & 0.92 \\
\hline DKA & $5 \quad(2.9)$ & 0 & $5(6.8)$ & 0 & $1(7.7)$ & 0.77 & 0.06 & & 0.33 & 0.33 & 0.91 & 0.35 \\
\hline Pneumonia & $13(7.7)$ & $5(8.3)$ & $6(8.3)$ & $2(8.3)$ & $2(15.4)$ & 0.88 & 0.98 & 1.00 & 0.99 & 0.99 & 0.44 & 0.60 \\
\hline UE & $7 \quad(4.1)$ & $3(5)$ & $2(2.8)$ & $2(8.3)$ & 0 & 0.76 & 0.66 & 0.62 & 0.26 & 0.26 & 0.55 & 0.53 \\
\hline $\mathrm{HE}$ & $2(1.2)$ & $2(3.3)$ & 0 & 0 & $1(7.7)$ & 0.54 & 0.20 & 0.37 & - & - & 0.15 & 0.35 \\
\hline GIT bleeding & $1 \quad(0.6)$ & 0 & $1(1.4)$ & 0 & 0 & 0.45 & 0.36 & - & 0.56 & 0.56 & 0.67 & - \\
\hline
\end{tabular}

Data was expressed in form of median or frequency (percentage). Data was expressed in form of median or frequency (percentage).

NG : Normoglycemic.

D : Diabetic.

SH : Stress Hyperglycemia.

ND : Newly Discovered DM.

MI : Myocardial Infraction.

DKA : Diabetic Ketoacidosis.

UE : Uremic Encephalopathy.

HE : Hepatic Encephalopathy.

GIT : Gastrointestinal Tract.

n: Number.

S: Significant.

1: Comparison among all groups.

2: Comparison between Normoglycemic and known DM.

3: Comparison between Normoglycemic and stress hyperglycemia.

4: Comparison between Normoglycemic and newly discovered DM.

5: Comparison between known DM and stress hyperglycemia.

6: Comparison between known DM and newly discovered DM.

7: Comparison between stress hyperglycemia and newly discovered DM. 
Table (3): Average daily blood glucose values for those with hyperglycemia.

\begin{tabular}{llll}
\hline Variables & \multicolumn{1}{c}{$\begin{array}{c}\text { Survivors } \\
(\mathrm{n}=124)\end{array}$} & $\begin{array}{c}\text { Non-survivors } \\
(\mathrm{n}=46)\end{array}$ & $\begin{array}{c}p- \\
\text { value }\end{array}$ \\
\hline Hemoglobin A1c & $7.3 \pm 2.96$ & $8.9 \pm 0.87$ & $0.001(\mathrm{~S})$ \\
Blood glucose: & & & \\
$\quad$ 1st day & $236.23 \pm 31.95$ & $268.88 \pm 61.66$ & $0.03(\mathrm{~S})$ \\
2nd day & $215.33 \pm 44.19$ & $253.15 \pm 55.23$ & $0.01(\mathrm{~S})$ \\
3rd day & $200.39 \pm 34.90$ & $228.50 \pm 23.56$ & $0.04(\mathrm{~S})$ \\
4th day & $185.81 \pm 21.89$ & $209.01 \pm 30.01$ & $0.01(\mathrm{~S})$ \\
& & & \\
Hospital stay (day) & $6(4-23)$ & $6(4-28)$ & 0.49 \\
Type of the patients: & & & \\
Normoglycemic & $53(42.7)$ & $7(15.2)$ & $0.001(\mathrm{~S})$ \\
Hyperglycemic & $71(57.3)$ & $39(84.8)$ & $0.001(\mathrm{~S})$ \\
Diabetics & $53(42.7)$ & $20(43.5)$ & 0.93 \\
Stress hyperglycemia & $7(5.7)$ & $17(37.0)$ & $0.001(\mathrm{~S})$ \\
Newly discovered DM & $11(8.9)$ & $2(4.3)$ & 0.52 \\
\hline
\end{tabular}

Data was expressed in form of mean \pm SD or median (range). $p$-value considered significant if $<0.05$.

S: Significant.

Table (4): Multivariate regression analysis for predictors of in hospital mortality in hyperglycemic patients.

\begin{tabular}{lccl}
\hline Variables & OR & $95 \%$-CI & $p$-value \\
\hline Age & 0.99 & $0.81-2.32$ & 0.91 \\
Presence of $>3$ comorbidities & 1.23 & $1.13-3.50$ & $0.001(\mathrm{~S})$ \\
Absence mof comorbidities & 0.33 & $0.29-3.90$ & 0.21 \\
Malignant disease & 1.27 & $0.88-2.15$ & 0.34 \\
Presence of chronic kidney disease & 1.48 & $0.95-2.37$ & 0.31 \\
Presence of coronary artery disease & 1.19 & $0.97-3.92$ & 0.21 \\
Elevated serum creatinine & 0.83 & $0.30-2.43$ & 0.07 \\
APACHE II score $>15$ & 1.72 & $1.21-3.51$ & $0.03(\mathrm{~S})$ \\
Stress hyperglycemia & 2.86 & $2.00-5.14$ & $0.001(\mathrm{~S})$ \\
Diabetes mellitus & 1.39 & $1.31-4.60$ & $0.001(\mathrm{~S})$ \\
Newly discovered DM & 0.43 & $0.27-2.18$ & 0.07 \\
\hline
\end{tabular}

Data was significant if $<0.05$.

OR : Odds Ratio.

CI : Confidence Interval.

APACHE II : Acute Physiology and Chronic Health Evaluation II.

S : Significant

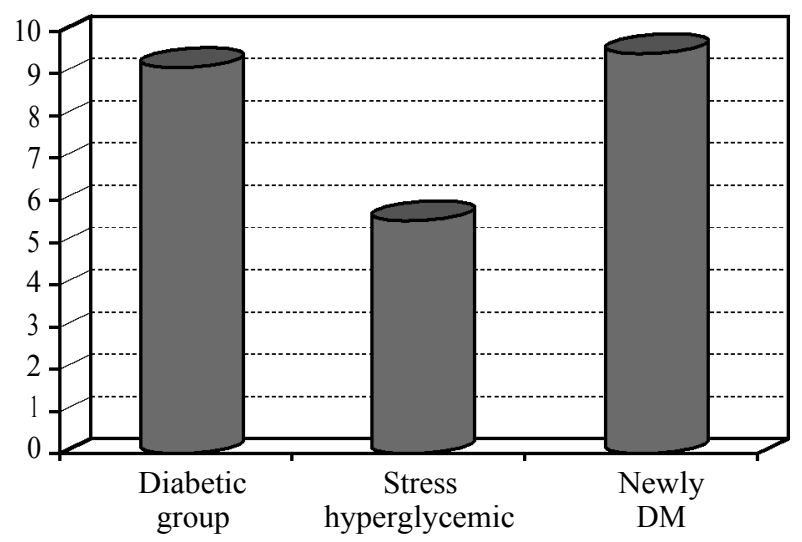

Fig. (1): HbAlc in the studied groups.

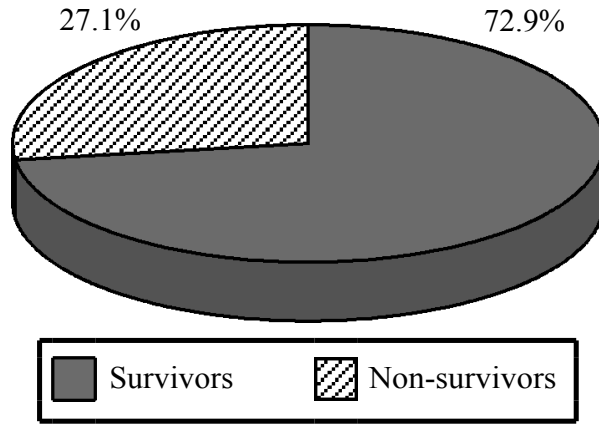

Fig. (2): Survivors and non-survivors among the studied patients.

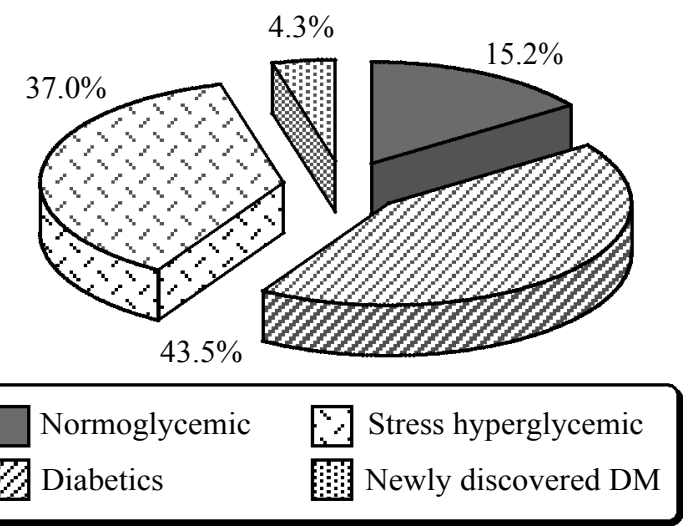

Fig. (3): Mortality in each studied group.

\section{Discussion}

Hyperglycemia associated with critical illness (also called ( $\mathrm{SIH})$ or stress diabetes) is a consequence of many factors, including increased cortisol, catecholamines, glucagon, growth hormone, gluconeogenesis, and glycogenolysis. Insulin resistance may also be a contributing factor, since it has been demonstrated in more than 80 percent of critically ill patient [11]. our study has included 170 patients admitted to ICU Unit of Internal Medicine Department at Assiut University Hospitals in period between July 1 st 2016 and 30th December 2016 were enrolled. In our study, the overall prevalence of patients with hyperglycemia was $64.7 \%$ (43\% with diabetes mellitus and $14.1 \%$ with stress hyperglycemia) which was higher than the study done by [4], where the overall prevalence of patients with hyperglycemia was 54\% (35\% with diabetes mellitus and $19 \%$ with a stress hyperglycemia). Also, this percentage was higher than in earlier studies where the prevalence of hyperglycemia was estimated at about $40 \%$ in studies done by $[4,12]$. In study of Filippo et al., [13] they found that patients with stress hyperglycemia had higher inhospital crude mortality $(7.9 \%)$ than those with diabetes $(5.7 \%)$ or those with normoglycemia $(3.9 \%)$ that was in agreement with our study where 
stress hyperglycemia was associated with the highest mortality rate $(37 \%)$.

Further, we found strong association between in-hospital hyperglycemia and adverse outcome in the form of higher mortality irrespective of presence of diabetes mellitus in patients admitted to ICU which was in consistent with Dhakal et al., [14].

By multivariate regression analysis for predictors of in hospital mortality in patients with hyperglycemia it was found that the presence of $>3$ comorbidities including diabetes and APACHE II score $>15$ were independent predictors for in hospital mortality in patients in studied groups.

\section{Conclusions:}

Stress hyperglycemia and diabetes mellitus were independent predictors for in hospital mortality in patients with hyperglycemia. Hyperglycemia is associated with increased risk of hospital complications and mortality in critically ill patients. So, meticulous and accurate intervention to control hyperglycemia particulary in critically ill patients is very important to reduce the morbidity, in hospital stay and lastly the mortality in critically ill patients.

\section{Recommendations:}

- Clinicians should have high index of suspicion of stress hyperglycemia in critically ill patients, especially when considering administration of intravenous or oral glucose in sick patients.

- All critically ill patients should be subjected to blood glucose monitoring and given appropriate management at the earliest stage to decrease morbidity and mortality.

- Measurement of HbA1C concentration during the hospital stay can assist in tailoring the glycemic management at discharge. Patients with $\mathrm{HbA} 1 \mathrm{C}<6.5 \%$ can usually be discharged with no antidiabetic medications just education. Patients with elevated $\mathrm{HbA} 1 \mathrm{C}$ can be treated with insulin or oral antidiabetic agents or combination therapy.

- Stress hyperglycemic patients may be prone to develop diabetes in future life, so they should advise for monitoring fasting, post prandial glucose and HbA1c as follow-up.

\section{References}

1- HARP J.B., YANCOPOULOS G.D. and GROMADA J.: Glucagon orchestrates stressinduced hyperglycaemia. Diabetes Obes. Metab., 18: 648-53, 2016.

2- DUNGAN K.M., BRAITHWAITE S.S. and PREISER J.C.: Stress hyperglycaemia. Lancet, 373: 1798-807, 2009.
3- ROBBA C. and BILOTTA F.: Admission hyperglycemia and outcome in ICU patients with sepsis. Journal of thoracic disease. Jul., 8 (7): E581, 2016.

4- GODINJAK A., IGLICA A., BUREKOVIC A., JUSUFOVIC S., AJANOVIC A., TANCICA and ADIS A. KUKULJAC: Hyperglycemia in Critically Ill Patients: Management and Prognosis. Med. Arh., Jun., 69 (3): 157-60, 2015.

5- McDONNELL M.E. and UMPIERREZ G.E.: Insulin therapy for the management of hyperglycemia in hospitalized patients. Endocrinol. Metab. Clin. North Am., 41: 175-201, 2012.

6- GRECI L.S., KAILASAM M., MALKANI S., KATZ D.L., HULINSKY I., AHMADI R. and NAWAZ H.: Utility of $\mathrm{HbA}(1 \mathrm{c})$ levels for diabetes case finding in hospitalized patients with hyperglycemia. Diabetes Care, 26 (4): 1064-8, 2003

7- MARIK P.E. and BELLOMO R.: Stress hyperglycemia. an essential survival response! Critical Care, 17: 305, 2013.

8- HSU C.W.: Glycemic control in critically ill patients. World J. Crit. Care Med., 1: 31-9.2 41, 2012.

9- ALI N.A., O'BRIEN J.M. Jr., DUNGAN K., PHILLIPS G., MARSH C.B., LEMESHOW S., et al.: Glucose variability and mortality in patients with sepsis. Crit. Care Med., Aug., 36 (8): 2316-21, 2008.

10- Diabetes Public Health Resource. Centers for Disease Control and Prevention. Hospital discharge rates for diabetes as any-listed diagnosis per 1,000 diabetic population, by age, United States, 1988-2009 [article online]. Available from https://www. cdc. gov/diabetes/statistics/ dmany/fig4. htm. Accessed 14 July 2016.

11-AGUS M.S., WYPIJ D., HIRSHBERG E.L., SRINIVASAN V., FAUSTINO E.V., LUCKETT P.M., ALEXANDER J.L., ASARO L.A., CURLEY M.A., STEIL G.M. and NADKARNI V.M.: Tight glycemic control in critically ill children. New England Journal of Medicine, Feb. 23; 376 (8): 729-41, 2017.

12- QASEEM A., HUMPHREY L.L., CHOU R., SNOW V. and SHEKELLE P.: Clinical Guidelines Committee of the American College of Physicians. Use of intensive insulin therapy for the management of glycemic control in hospitalized patients: A clinical practice guideline from the American College of Physicians. Ann. Intern. Med., Feb. 15; 154 (4): 260-7, 2011.

13- FILIPPO P., CRISTINA B., ALESSIA F., CARLOTTA C., ANDREA C., FRANCESCO C., ALBERTO M.P., ALESSANDRO M. and CARLO N.: The classification of hospitalized patients with hyperglycemia and its implication on outcome: Results from a prospective observational study in Internal Medicine Intern. Emerg. Med., 11: 649-56, 2016

14- DHAKAL M., DHAKAL O.P. and BHANDARI D.: Hyperglycemia in critically ill patients and its association with increased mortality. A hospital based observational study. International Journal of Medical Research and Review, Apr. 30; 4 (04), 2016. 


\section{إرتفاع السكرى عند دخول الهستشفى

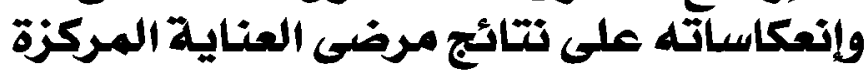

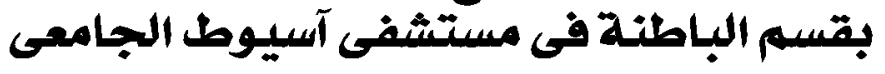

الدراسة تضمنت مائة وبسعون مريضا في وحدة العناية المركزة في قسم الطب الباطنى بمستشفيات جامعة آسيوط في الفترة ما بين يوليو

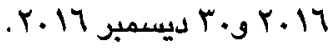

تم تصنيف هؤلاء المرضى إلى الهجموعات التالية:

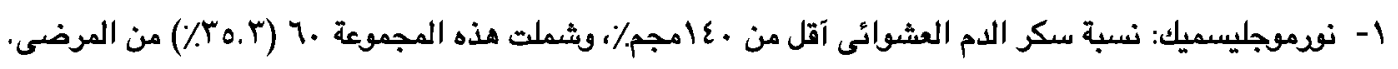

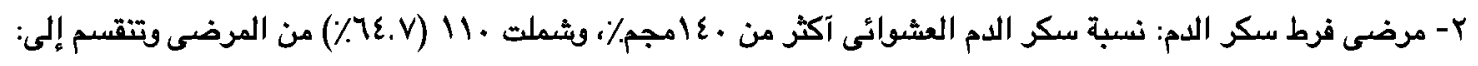

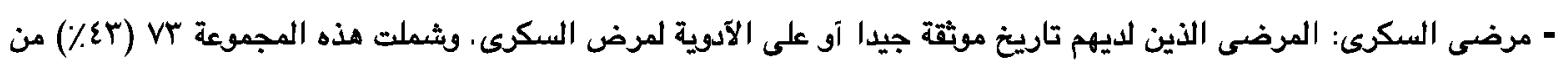
المرضى.

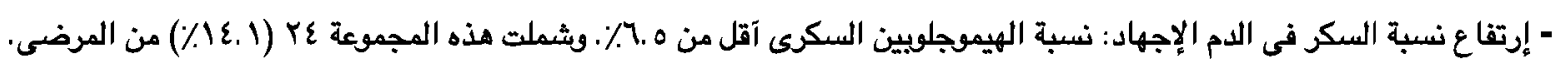

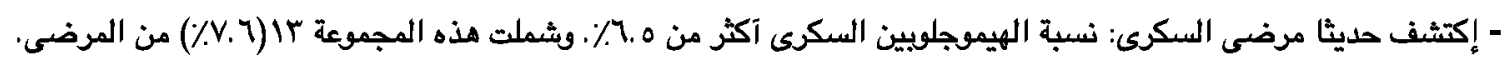

